\title{
Backsourcing and knowledge re-integration: a case study
}

\author{
Bella Belerivana Nujen ${ }^{1}$, Lise Lillebrygfjeld Halse ${ }^{1}$, Hans Solli-Sæther ${ }^{2}$ \\ ${ }^{1}$ Molde University College, Specialized University in Logistics, Molde, Norway \\ \{Bella.B.Nujen, lise.l.halse\} @himolde.no \\ 2 Ålesund University College \\ haso@hials.no
}

\begin{abstract}
Recently, the interest in the phenomenon of backsourcing has increased, which has been inspired by awareness of the real costs of global outsourcing and the importance of keeping manufacturing in-house or in geographical proximity. However, backsourcing research is still in its infancy. In particular, this strategy requires a successful knowledge re-integration process when organizations employ backsourcing as their new sourcing strategy, which is addressed in this paper. To expand the understanding of backsourcing, a literature review of this phenomenon is given, and based on findings from a case company in the Norwegian shipbuilding industry, we present critical success factors for knowledge re-integration when bringing manufacturing back in-house.
\end{abstract}

Keywords: Backsourcing, Global outsourcing, Knowledge re-integration.

\section{Introduction}

Few logistic trends have caught as much attention from academics and practitioners as has outsourcing [1]. Today, there are indications that the complexity of outsourcing strategies will increase over time [2,3], making insight of sources of competitive advantages and core competencies more important than ever. The growing amount of literature within SCM and outsourcing, stress that a number of global relationships and outsourcing contracts have failed to deliver on the promises they set out to achieve $[4,5]$. Such experiences have made businesses reconsider their strategies, and instead started to recall value creation processes back in-house, which previously have been outsourced to third-party companies. The early academic literature within the field of backsourcing, claims that backsourcing can be motivated by changes in the environment, redefinition of the characteristics of the outsourced activities or dissatisfaction of the initial assessment that had led to outsourcing $[2,5,6]$. However, backsourcing may introduce difficulties to organizations when they make the decision to bring value creation processes back in-house that previously have been outsourced. The client and the vendor organization might have developed contradictory or incompatible routines, codes and cultures, which may hamper the process of the reintegrated activity [7]. The success of re-integrating an outsourced process will to a large extent depend on how well the organization manages to capture and understand what types of knowledge that needs to be re-integrated. The organization will have to take charge

adfa, p. 1, 2011.

(C) Springer-Verlag Berlin Heidelberg 2011 
of their competences again, or develop new capabilities [8]. At the same time, organizations also have to make sure that the appropriate type of knowledge fits in the new structure. Consequently, backsourcing represents a significant challenge in terms of re-transferring and re-integrating knowledge, value chain activities and skills. Therefore, it is essential for the organization to (re)build a required structure and acquire or maintain employees with the right type of knowledge base. However, there is a conspicuous absence of studies on backsourcing in the literature [2]. Specifically, we need to understand the drivers of this strategy, and identify the challenges that come with this global-local shift, and furthermore, the risk of losing vital knowledge, especially in relation to core competences. These issues are addressed in this paper

The rest of the paper is organized as follows: First, we present theory related to sourcing strategies, concluding with the need to studies of backsorucing, where the knowledge dimension is highlighted. We briefly address the methodology used in this study, and present the case company and the findings. Finally, we present the discussion, conclusions and contribution of this paper.

\section{Literature review}

\subsection{From global sourcing to backsourcing}

Global outsourcing, also referred to as offshoring, can be defined as the relocation of some organizational activities such as information technology, finance, human resources, back office etc. to a subsidiary or independent providers across national borders [9], which is different from an outsourcing strategy. In global outsourcing/offshoring strategies, the relocation of activities can be organized both within and outside the boundaries of the organization, encompassing both a captive model (offshoring to a new e.g. factory which is owned by the organization), and offshore outsourcing (offshoring to an independent third party) [7, 10]. Nowadays, global outsourcing of central supply chain activities as manufacturing is the norm. By adopting this strategy, and specializing on limited activities, outsourcing companies have to some degree been able to improve cost efficiency, and enhancing their core competence activities [11-13]. However, the actual benefits of outsourcing have been increasingly challenged, which have led businesses to embrace alternative methods of activity relocation. The different relocation processes which have emerged from the evolution of existing global value chain strategies, are referred to by relatively new terms such as; reshoring, backshoring, inshoring, nearshoring, re-insourcing and backsourcing. This includes relocation of value creating activities to a neighboring country or a recall of these activities back to their home country, as well as reincorporated into their focal firm where the latter is perceived as the latest phenomenon [2, 9, 14-16].

In this study, we make a distinction between the novel terms reshoring, backshoring and backsourcing since they seem to converge in different studies. Reshoring, also referred to as backshoring, is generally defined as moving manufacturing back to the country of its mother organization while others describes it as a location decision only, as opposed to decision regarding location and ownership [15]. Reshor- 
ing/backshoring is concerned with where manufacturing activities are to be performed, independent of who is performing the manufacturing activities in question. The new phenomenon called backsourcing, on the other hand, denotes a recall of activities back in-house that previously have been (globally) outsourced [7], with the goal of rebuilding internal capabilities [2, 5], and distinguishes itself from reshoring/backshoring by being depended of the ownership structures. The definition of [5] implies that the decision to backsource is made after considerations whether to extend, renew, renegotiate an existing contract, re-tend with another vendor, or bring back the operation in-house in order to rebuild own competences and capabilities regarding the specific process, which is the definition we support in our study.

While the scale of this relocation activity, especially the backsourcing phenomenon, still is modest, a large number of businesses aspire to have strategic IT and business process activities performed locally $[5,7,17]$. Comparable drawbacks have been debated in general, and it has frequently been claimed that outsourcing might have gone too far.

\subsection{Sourcing strategies and knowledge}

Knowledge is as a complex phenomenon with several different dimensions, and is regarded as the critical resource of organizations and economies [18]. According to Polanyi [19] knowledge is a process which extends itself through a wide dimension where at one extreme, knowledge is almost completely structured and explicit and therefore also available for others than the active knowers originating it. At the other end of the dimension however, knowledge is almost exclusively tacit, that is halfconscious and unconscious knowledge embedded in human cognition and action. Furthermore, the latter dimension of knowledge is characterized as being highly personal, abstract and difficult to communicate by verbal articulation, Moreover, the main source of tacit knowledge creation is a result of experiences performed by the individual(s). However, all organizations and supply chains contain a mixture of these dimensions, and their relative importance may differ. What is important in an outsourcing context is how external institutions interact with the internal organizational structures and activities to generate the right type of knowledge [18]. Local embedded knowledge is the collective form of tacit knowledge, which is based on shared perceptions and understanding of a context specific situation, which according to [18] facilitates effective communication so it can be maintained. However, embeddedness is often lost when crossing borders, as organizations encounter different cultural and institutional settings [18].

Given that a lot of outsourcing occurs across national borders, organizations are dealing with some sort of "knowledge exchange". Backsourcing involves reintegration of knowledge, which is complex and hard to concretize. Hence, the success of this strategy will be depended on the ability to understand what types of knowledge needed to be re-integrated. Consequently, the organization has to activate or develop new capabilities [8]. Moreover, the re-integrated knowledge also has to fit within the new structure, since it probably will not return to the same situation. Acquiring or maintaining employees that possess the right type of knowledge base is 
therefore of significant importance when re-transferring knowledge [2]. Strategizing effective methods to transfer knowledge between people from different organizations, within different supply chains, all of which are carrying different knowledge platforms is not an easy task to manage [20]. With global value chains and global outsourcing strategies, this might even be more challenging since the tacit dimension of knowledge is not only related to the human dimension, it is also geographically and culture sensitive which makes it context specific [18].

\subsection{Research problems}

While there is a huge amount of literature dealing with global outsourcing, there is a conspicuous absence of studies on backsourcing [2, 17]. Furthermore, previous studies are primarily focusing on cost considerations and secondly on location decisions [21, 22], rather than with the challenges that comes with this global-local shift and the risk of losing vital knowledge especially in relation to core competences. This study aims at filling these gaps in the literature firstly by studying the backsourcing decision process in order to understand the motivation behind this strategy. Secondly, we focus on the process of re-integrating knowledge. Finally, we wish to shed some light on other potential advantages experienced by pursuing a backsourcing strategy.

\section{$3 \quad$ Methodology}

The above research issues calls for a deeper analysis of the phenomena, making a case study design appropriate. According to Yin [23], the case study design is especially relevant the more the research question seeks to explain 'how' and 'why' some social phenomena works, and is particularly important for explorative studies aiming at developing theory [24]. Few studies have studied the phenomenon of backsourcing, and an explorative case design is therefore chosen.

According to Yin [23], the rationale of selecting a single case study, is that it represents the critical, unique, representative, revelatory and/or a longitudinal case. The case company in this study is one of the first members in its industry to implement this sourcing strategy, and have received considerable attention associated with this. Therefore, this case represents a unique opportunity to analyze the recent phenomenon of backsourcing decisions and implementation in-depth. The main data collection was performed through in-depth, semi-structured interviews of key personnel in the company. In addition, a study of published documents regarding the outsourcing decision in the case company has been carried out.

\section{The case company}

The case company in this study is one of the largest Norwegian-owned shipbuilding organizations and is part of the unique Norwegian maritime cluster, located at the Northwest coast of Norway [25]. The cluster has demonstrated its ability to innovate 
and grow, by continuously developing new business areas and expand its knowledge base. It is claimed that the close interaction between the different companies, which members whom are sharing knowledge is the main strength of the cluster, where the tacit dimension of knowledge is a critical factor [25]. However, even if local embedded knowledge is regarded as key to long-term cluster success and survival, we still see a greater tendency towards a local-global shift. Already during the 1990's, global sourcing of vessel construction was attracting more attention, where considerations such as cost efficiency had a strong focus, leading some cluster members to embark on an outsourcing strategy where the constructions of hulls was moved to Eastern European countries. Several companies pursued a strategy involving increased global sourcing, which had a direct impact on traditional production principles with regard to the actual construction of hulls. From being module based, to building the complete hull before equipping the vessels. The upstream side of the cluster supply chains was no longer limited to a local area, but rather to a global one. The implication of this new strategy was that these organizations had outsourced what they once regarded as parts of their core activities, such as the design and construction of complete vessels. This later expanded to also include other activities of the ship constructing process, like engineering. The decision to outsource these former core business activities were mainly based on cost considerations, as a way for the organization to maintain a competitive edge and concentrate on other core activities. Hence, the focus in the industry shifted from production towards their building capabilities in developing new technological solutions and knowledge of more efficient maritime operations. The case company in this study also embarked on an outsourcing strategy in the late 1990s, by offshoring steel production and welding work to external parties in Poland.

\section{$5 \quad$ Findings}

\subsection{The backsourcing decision}

The backsourcing decision in the case company was not a result of a deliberate strategic process, but rather a result of an incidental event. In 2004, the company was competing for a contract on six small vessels, where the customer required delivery only after 10 months, which was impossible to accommodate within the existing setup. . In order to meet the customer's requirements, it was decided to modularize and construct the hull at their own slipway, which they reopened for this contract, as it had been closed since the late 1990s. This event took place about the same time as the Eastern European countries entered the EU, which opened up for free access and flow of labour, something that resulted in lower labour costs then before which gave them an advantage without using a third part company. Furthermore, as a result from this experience, being able to adapt to the constantly changed environment and to compete with low-cost countries, the company chose to learn from other industries such as the furniture- and automobile industry, where automation was the norm. By developing their methodology and their equipment so that they could handle larger and heavier modules than before, the company implemented a technology focused strategy and invested heavily in automation and robotics at all levels in their business. 


\subsection{Re-integration of previous outsourced knowledge activities}

Even if this case company's backsourcing journey started as a coincidence, they now have a clear and deliberate strategy towards backsourcing even more capabilities

During the backsourcing process, the case company had re-evaluated their core competence to also include steel construction as source of their most important competitive advantages. In fact, the company's technology focus by using robotics in production was a contributing factor for steel production to be considered as a part of the core business again. Further, it also revealed that domestic labor costs became less relevant through automation, since the company thereby managed to achieve reducing their working hours. Additionally, to be able to change their sourcing strategy they saw the need to keep their tacit knowledge within their own organization. The company stresses that the backsourcing operation would not have been achievable without any in-house competence. Furthermore, the time aspect was also claimed to be crucial. The longer time that has passed since the outsourcing decision, the higher the probability to lose manufacturing knowledge is. Hence, the most important staff that worked on building modules and had hull-expertise was still a part of the organization.

Moreover, the modularization process was found to be a significant competitive advantage for the company. Building the models separately, increased flexibility and reduced capacity problems, which led to increased efficiency. The process also became useful in relation to prevent suppliers to grow into competitors, since the complex product design (modulation) was an effective way to protect important knowledge.

However, they also saw the need to develop new capabilities since they had a desire to backsource while they still had access to their employee's knowledge. They reevaluated the importance of engineering and considered it as a part of their core value, as a skill they needed to have control of. Further, in order to be able to backsource without increasing the total costs in a long-term perspective and at the same time be able to compete with low-cost countries, they need to continue to invest in automation and therefore renew their knowledge platform. Consequently, in addition to their existing knowledge dimensions, they also were in need of a more technological competence/skill set. In order to satisfy this acknowledgment, the company has implemented a deliberate HR-strategy in relation to these new requirements. By hiring people with the right type of automation know-how and then strategically encourage knowledge sharing within the organization through learning by doing or experience-based collective action between different disciplines within the different departments, the company have achieved to motivate their workers to adopt the new technical changes through better knowledge flow processes.

\section{Discussion and conclusions}

The main finding in this study is that the presence of in-house organizational knowledge platform has been a vital criterion for backsourcing success in the case company. When embarking a backsourcing strategy, it seems to be of significant im- 
portance that specific know-how and tacit knowledge representing or being close to an organization's core competence, is kept within the organizations own boundaries. Aspects of a still existing knowledge base enabled a renewal of the knowledge platform by combining robotics- and automation skills with steel- and welding competence within this company. Furthermore, the stakeholders interviewed also acknowledged the need for shipbuilding knowledge as one of the main drivers to backsourcing.

One important success factor in the backsourcing process has been the time aspect. The less time the organization has had a particular activity outsourced, the easier it was to backsource, since the chances for important knowledge to still exist seems to be greater. Furthermore, the fact that the organization had remained relatively similar as it was before the outsourcing decision, facilitated the re-integration of knowledge through backsourcing. Even if the organization might have new structures and/or new leadership, it usually takes a long time to change culture aspects of an organization, which is of great importance when one is trying to manage and/or locate knowledge transfer processes. Moreover, the case company was operating in a knowledge intensive industry, where a strong dimension of tacit knowledge within the cluster have been built up over generations and was embedded in the industrial context $[25,26]$, which created an awareness of not letting traditional shipbuilding competence erode. This may have been a contributing factor to keeping the knowledge within the organization. Through the backsourcing strategy supported by modularization and robotics, the company achieved more flexibility and at the same time enhanced their ability to retain production and embedded tacit knowledge in Norway, while still achieving operational advantages.

Although the method limitation involving a single case study, we conclude that organizations should consider their manufacturing decisions from a wider perspective than simply make or buy decisions, giving more weight to supply chain issues as well as strategic factors concerning retaining and renewal of organizational knowledge platforms. Future studies should examine the knowledge re-integration process in more detail, and include several companies.

\section{$7 \quad$ References}

1. Stojanović, Đ.: Paradoxes and opportunities in logistic outsourcing research. Promet Traffic \& Transportation 24(6), 525-533 (2012)

2. Bhagwatwar, A., Hackney, R., Desouza, K.C.: Considerations for Information Systems "Backsourcing": A Framework for Knowledge Re-integration. Information Systems Management 28(2), 165-173 (2011)

3. Dibbern, J., et al.: Information systems outsourcing: a survey and analysis of the literature. SIGMIS Database 35(4), 6-102 (2004)

4. Baier, E., Rammer, C., Schuber, T.: The impact on innovation off-shoring on organizational adaptability, in ZEW Discussion Papers (2013)

5. Lacity, M.C., Willcocks, L.P., Rottman, J.W.: Global outsourcing of back office services: lessons, trends, and enduring challenges. Strategic Outsourcing: An International Journal $1(1), 13-34(2008)$ 
6. Veltri, N.F., Saunders, C.S., Kavan, C.B.: Information Systems Backsourcing: Correcting Problems And Responding to Opportunities. California Management Review 51(1), 50-76 (2008)

7. Oshri, I., Kotlarsky, J., Willcocks, L.: The handbook of global outsourcing and offshoring. New York: Palgrave (2011)

8. Overby, S.: Lost in tranlation. IT World Canada News (2004) www.itworldcanada.com/article/lost-in-translation/16746, [cited 2013 10. april]

9. Ellram, L.M., Tate, W.L., Petersen, K.J.: Offshoring and Reshoring: An Update on the Manufacturing Location Decision. Journal of Supply Chain Management 49(2), 14-22 (2013)

10. Lewin, A.Y., Massini, S., Peeters, C.: Why are companies offshoring innovation? The emerging global race for talent. Journal of International Business Studies 40(6), 901-925 (2009)

11. Quinn, J., Hilmer, F.: Strategic Outsourcing. Sloan Management Review (Summer), 43-55 (1994)

12. Ellram, L., Billington, C.: Purchasing leverage considerations in the outsourcing decision. European Journal of Purchasing \& Supply Management 7(1), 15-27 (2001)

13. Kakabadse, A., Kakabadse, N.: Outsourcing: Current and Future Trends. Thunderbird International Business Review 47(2), 183-204 (2005)

14. Contractor, F.J.: Global outsourcing and offshoring: an integrated approach to theory and corporate strategy.Cambridge: Cambridge University Press (2011)

15. Gray, J.V., et al.: The Reshoring Phenomenon: What Supply Chain Academics Ought to know and Should Do. Journal of Supply Chain Management 49(2), 27-33 (2013)

16. Fratocchi, L., et al.: Manufacturing Back-Reshoring - An Exploratory Approach for Hypotheses Development, in XXIV Riunione Scientifica Annuale Associazione italiana di Ingegneria Gestionale, "Entrepreneurship, innovation and the engine of growth". Politecnico di Milano, Milano (2013)

17. Whitten, D., Leidner, D.: Bringing IT Back: An Analysis of the Decision to Backsource or Switch Vendors. Decision Sciences 37(4), 605-621 (2006)

18. Lam, A.: Tacit knowledge, organizational learning and societal institutions: An integrated framework. Organization Studies 21(3), 487-513 (2000)

19. Polanyi, M.: The tacit dimension. Garden City, N. Y.: Doubleday (1967)

20. Nonaka, I., Takeuchi, H.: The knowledge-creating company: how Japanese companies create the dynamics of innovation. New York: Oxford University Press (1995)

21. Da Silveira, G.J.C.: An empirical analysis of manufacturing competitive factors and offshoring. International Journal of Production Economics 150, 163-173 (2014)

22. Kinkel, S., Maloca, S.: Drivers and antecedents of manufacturing offshoring and backshoring-A German perspective. Journal of Purchasing and Supply Management 15(3), 154-165 (2009)

23. Yin, R.K.: Case study research: design and methods. Los Angeles: Sage (2009)

24. Voss, C., Tsikriktsis, N., Frohlich, M.: Case research in operations management. International Journal of Operations \& Production Management 22(2), 195 (2002)

25. Halse, L.L., Bjarnar, O.: Social fields of knowledge flows: A regional cluster in a global context, in The social dynamics of innovation networks: From learning region to learning in socio-spatial context, R. Rutten, et al., Routledge (2014)

26. Solli-Sæther, H., Karlsen, J.T.: Knowledge transfer in shipbuilding projects: a study of facilitating mechanisms. International Journal of Project Organisation and Management 4(3), 256-271 (2012) 